\title{
REGULATORY T CELLS (TREG) AND THEIR ROLES IN IMMUNE SYSTEM WITH RESPECT TO IMMUNOPATHOLOGICAL DISORDERS
}

\author{
Kateřina Kondělková ${ }^{1}$, Doris Vokurková ${ }^{1}$, Jan Krejsek ${ }^{1}$ Lenka Borská $^{2}$, Zdeněk Fiala ${ }^{3}$, Ctirad Andrớs ${ }^{1}$ \\ Charles University in Prague, Faculty of Medicine and University Hospital Hradec Králové, Czech Republic: Department \\ of Clinical Immunology and Allergology ${ }^{1}$; Institute of Pathological Physiology ${ }^{2}$; Institute of Hygiene and Preventive \\ Medicine $^{3}$
}

\begin{abstract}
Summary: Regulatory $\mathrm{T}$ cells (Tregs) are a specialized subpopulation of $\mathrm{T}$ cells that act to suppress immune response, thereby maintaining homeostasis and self-tolerance. It has been shown that Tregs are able to inhibit $\mathrm{T}$ cell proliferation and cytokine production and play a critical role in preventing autoimmunity. Different subsets with various functions of Treg cells exist. Tregs can be usually identified by flow cytometry. The most specific marker for these cells is FoxP3, which is localized intracellulary. Selected surface markers such as CD25 high (high molecular density) and CD127 low (low molecular density) could serve as surrogate markers to detect Tregs in a routine clinical practice. Dysregulation in Treg cell frequency or functions may lead to the development of autoimmune disease. Therapeutical Treg modulation is considered to be a promising therapeutical approach to treat some selected disorders, such as allergies, and to prevent allograft rejection.
\end{abstract}

Key words: Regulatory T cells, Immunopathology, Regulation

\section{Mechanisms of immune regulation}

A critical feature of immune system is homeostasis maintenance. Based on this characteristic, immune system inhibits the development of autoimmunity, but induces an effective immune response against microbial challenge (29). The immune system contains potent mechanisms that eliminate pathogenic microorganisms and infected cells, and parallel regulatory mechanisms that keep effector cells under control during physiological conditions and after activation elicited by an inflammatory process. Effective regulation of the inflammation is required to reduce the tissue damage caused by an excessive immune activation.

At the end of 1980's, Mosmann and Coffman established a functional categorization of Th cells (24). Th cells were thought to be divided into two separate populations, which perform their effector functions via cytokines. Th 1 cells are secreting INF- $\gamma$ and IL-2, while Th2 cells produce mainly IL-4, IL-5, and IL-13. Th1 cells are involved in macrophage activation and cytotoxic killing of intracellular pathogenes. In addition, they also play a role in autoimmune diseases such as the $4^{\text {th }}$ type of hypersensitivity reaction and chronic infections. Th2 cells, on the other hand, are regulating B cells for production of immunoglobulins, including IgE class, thus play a role in allergy and defence against helminthic parasites. Th1 and Th2 T cells are in an antagonis- tic relationship and their balance is important for efficient immune response.

In 2003, a subset of T cells designated regulatory T cells (Tregs) was found to express the transcription factor FoxP3, and was identified as a pivotal part for control of the inflammatory processes (14). Sakaguchi et al. demonstrated in mice that displacement of Treg by neonatal thymectomy led to multiple organ autoimmunity. This process could be reversed by adoptive transfer of these $\mathrm{CD} 4+\mathrm{CD} 25+\mathrm{T}$ cells (28).

Veldhoen et al. and Bettelli et al. independently discovered highly proinflammatory Th subset secreting IL-17 called Th17 cells $(2,34)$. It is known that Th17 cells are different from Th1, Th2, and Treg cells, and have an influence on autoimmunity, allergy, tumor development, and organ transplantation. Th17 differentiation is induced by TGF- $\beta$ and IL-6. This subset produces a number of cytokines, such as IL-6, IL-17A, IL-17F, IL-20, IL-22, IL-26, and TNF- $\alpha$, respectively (reviewed in 8). Fig. 1 reflects ours perceptions about regulation relationship between $\mathrm{CD} 4+\mathrm{T}$ cell subsets.

Among Treg cells, four unique populations of CD4+ T cells have been identified so far (natural CD4+ Treg cells, Th 3 cells, Tr1 cells, and CD8+ Treg cells) that are directly involved in the regulation of immune responses to pathogens, allergens, and self-antigens (reviewed in 25). 


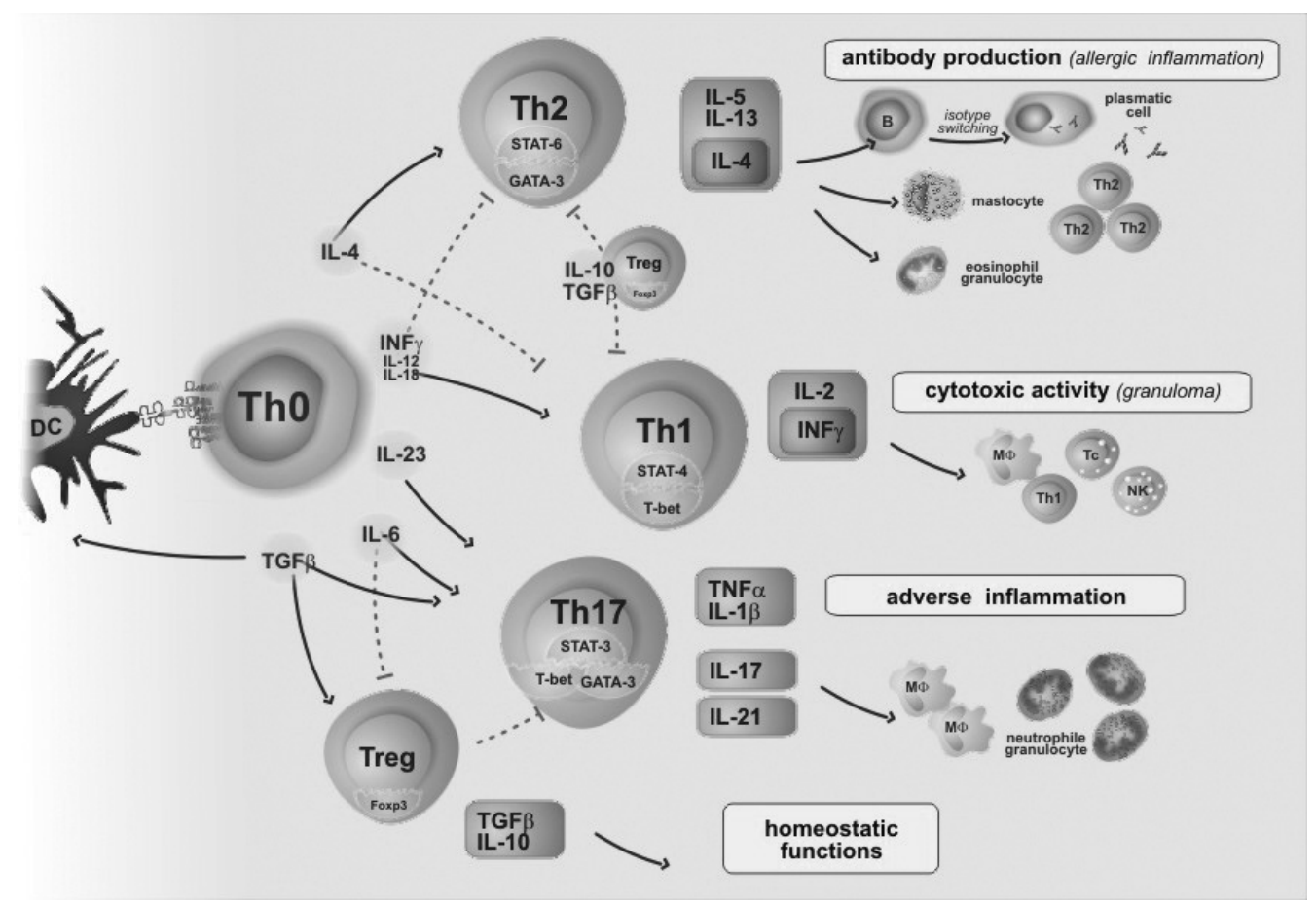

Fig. 1: Regulation relationship between $\mathrm{CD} 4+\mathrm{T}$ cell subsets.

\section{Detection of Tregs}

The best method which is now available to identify Treg cells is flow cytometry. The capture and analysis of these cells requires multiple markers. A common approach to the identification and isolation of Tregs is exploiting CD4+ and CD25+ expression. It is a difficult task to identify Treg cells by flow cytometry, as the most specific marker FoxP3 is localized intracellulary $(5,6,29)$. That is, why FoxP3 detection is only possible after cell permeabilization. Permeabilization step is not very advantageous for routine laboratory testing. However, it has been recently recognized that FoxP3+ cells are expressing a subunit of IL-7R, CD127, in a significantly lower density. It was proved experimentally that $\mathrm{CD} 4^{+} / \mathrm{CD} 25^{\text {high }} / \mathrm{CD} 127^{\text {low }}$ cells are Fox $\mathrm{P} 3+$. It is now generally accepted that this phenotype can serve as a surrogate marker for Treg cells (22). For routine testing, CD25 $5^{\text {high }} / \mathrm{CD} 127^{\text {low/- }}$ phenotype is enough specific and sensitive to identify Treg.

\section{Different types of Treg cells}

Several subsets of Treg cells have already been identified, such as natural CD4+ Treg cells, Th3 cells, Tr1 cells, and CD8+ Treg cells, respectively. It is very likely that the other distinct subsets will be added to this list in future.

Natural Treg cells represent 5-10\% of total CD4+ helper inducer $\mathrm{T}$ cells $(4,32)$. They are characterized by the intermediate to high expression of the cell surface IL-2 receptor
(CD25), as well as the intracellular expression of transcription factor FoxP3. Whereas suppression in many model systems in vivo and in vitro is mediated by the secretion of the suppressor cytokines, the mechanism of suppression mediated by CD4+CD25+ cells appears to be mediated by cellto-cell contact- dependent mechanism $(2,31,32)$.

Phenotype of $\operatorname{Tr} 1$ cells is CD25-FoxP $3^{-} \mathrm{CD} 4^{+}(1)$. These cells, upon activation via the TcR, produce high amounts of IL-10 and very low levels of IL-2, but they do not produce IL-4 (5). Battaglia et al. demonstrated that $\operatorname{Tr} 1$ cells are beneficial for the induction of tolerance to self-, allo-, and non-harmful foreign antigens, such as food antigens (1). $\operatorname{Tr} 1$ cells inhibit both the proliferation and cytokine production of effector T cells, and the function of APCs in an IL-10 dependent manner (20).

Th3 cells are phenotypically resemble $\operatorname{Tr} 1$ cells, but their principal modulator is TGF- $\beta(3,15,35)$. Th 3 cells provide a help for IgA synthesis and chemotaxis of leukocytes. They have suppressive properties for Th1 and other immune cells. The production of TGF- $\beta$ by Th 3 is critical for the maintainance of tolerance at mucosal surfaces, exemplified by oral tolerance induced by feeding of antigen at low dosage (20).

\section{Functional properties of Treg cells}

The crucial role of $\mathrm{T}$ cell system in the pathogenesis of immunopathological disorders is fully accepted now. T cells are responsible for the induction of autoimmune immuno- 
pathological processes, their development, extent, and putative resolution. Regulatory Treg cells participate in the maintainance of peripheral tolerance (10). Sakaguchi et al. confirmed that Treg cell activity is regulated by numerous costimulatory interactions and cytokine microenvironment both in thymus and in tissues to maintain autotolerance (28). They display the most potent immunosuppressive potential among cell populations tested (17).

Mature Treg cells are released from thymus after stimulation by chemokines and other mediators emanating from the location of tissue injury and inflammation. They nonrandomly migrate into these sites and corresponding lymphoid tissues (13). Jonuleit et al. reported that Tregmediated immunosuppression is a result of their direct interactions with effector cells (17). It is thought that IL-2 overproduction is inhibited by Treg cells with a subsequent downmodulation of CD $25 \alpha$ subunit of IL-2 receptor. There is a feedback control of Treg cells activation $(29,32)$.

Tregs are characterized as a functionally highly specialized $\mathrm{T}$ cell subset responsible for the optimalization of immune response. Treg cells are able to downmodulate unwanted activities of autoreactive clones of $\mathrm{T}$ cells, such as their activation and clonal expansion. Treg cells participate in induction and maintainance of immune tolerance by recognition of autoantigens which are released from injured tissues with subsequent modulation of immune response, mediated by either intimate cell to cell contact or via soluble cytokines $(32,36)$.

Vojdani et al. published that Treg cells mediate the prevention of autoimmunity in two ways. The first one involves the prevention of autoreactive $\mathrm{T}$ cell priming and differentiation in the draining lymph nodes. Treg cells located around dendritic cells in the lymph nodes can prevent the early stages of $\mathrm{T}$ cell activation. The second action of Treg cell suppression involves the activation, proliferation, and subsequent trafficking of Treg cells to the affected tissue to restrain effector cell functions locally (reviewed in 37).

Another mechanism of Treg cells action is their cytotoxic activity which is mediated by granzymes and perforin release. Numerous target cells e.g. CD4+ and CD8+ subpopulations of T cells $(9,11)$, NK and NKT cells, monocytes, dendritic cells and granulocytes are regulated by this cytotoxic activity of Treg cells $(26,31,33)$. Tregs are able to restrict CD8+ memory effector T cells $(19,26)$. Thus, it is conceivable that increasing of the number of cutaneous Treg cells could diminish pathogenic CD8+ T cell functions in the inflammatory process of psoriasis (21).

Chen et al. emphasized that the balance between activated effector cells and Treg cells is important for efficient immune response (16). Upregulation of Treg cell function or increase in the number of these cells might be beneficial for treatment of autoimmune diseases and allergies, and for prevention allograft rejection. Moreover, inhibiting Treg cell function or decreasing Treg number might assist immunity against tumors and pathogenic microorganisms (25).
Skin is normally covered with innocuous and weakly immunogenic normal bacterial, viral, and fungal flora, to which vigorous ongoing immune responses would cause immunological chaos and chronic inflammation. Tregs limit effector $\mathrm{T}$ cell activation to this normal nonpathogenic resident flora, while permitting the necessary $\mathrm{T}$ cell activation to acute infection $(12,18)$.

The ability to induce Treg cells and to promote their long-term survival in the periphery could be the proof of efficacy of immunosuppressive therapy. Tr 1 cells could be induced from naive $T$ cells by repeated stimulation of their TcR in the presence of IL-10 (1). Battaglia et al. demonstrated that functional $\operatorname{Tr} 1$ Tregs are also produced by direct association of CD46 membrane molecule with CD3 complex in the presence of IL-2 (1). TGF- $\beta$ has a major positive role in the generation, function, and survival of adaptive CD4+ and CD8+ Treg subsets (reviewed in 38). Cultivation of naive T cells simultaneously with TcR stimulation in the presence of IL- 2 and TGF- $\beta$, results in up-regulation of expression of FoxP3 transcription factor. These induced Tregs are capable of inhibiting proliferation of effector T cells (38). By maintaining the pool size of natural CD4+CD25+ cells in periphery, TGF- $\beta$ plays an important role in Treg homeostasis. Thus, it has become evident that TGF- $\beta$ displays effects on both natural and adaptive Treg cells (23). IL-2 is critical for homeostasis, function, and development of Treg cells. Treg cells cannot expand their numbers, survive, or suppress $T$ cell proliferation in the absence of IL-2 $(20,38)$. Zheng et al. demonstrated that synergistic effects of IL-2 and TGF- $\beta$ can induce naive CD4+ cells to become CD25+FoxP3+ suppressor cells that express characteristic markers of natural Treg cells (38).

\section{Treg cells in immunodeficiency and immunopathological diseases}

Deficiency in FoxP3 due to genetic mutations results in the immunodysregulation, polyendocrinopathy, enteropathy, $\mathrm{X}$ linked (IPEX) syndrome. This multiple autoimmune disorder is characterized by severe intestinal pathology, with massive $\mathrm{T}$ cell infiltration, type 1 diabetes mellitus, eczema, anemia, liver infiltration, thrombocytopenia, hypothyroidism, and the presence of a variety of autoantibodies. Death typically occurs in early childhood, unless treated with aggressive immunosuppression, hematopoietic stem cell transplantation, or both $(20,25)$.

Alpha subunit of IL-2 receptor, CD25 molecule, is one of the key surface marker of Treg cells. Deficiency of CD25 molecule results in chronic inflammation in the intestine and lungs. Infectious complications similar to those observed in patients with $\mathrm{T}$ cell deficiency, such as recurrent cytomegalovirus-induced pneumonitis, candidal infections, and chronic gastrointestinal diseases, are present in CD25 deficient patients. Patients lacking CD25 suffer from biliary duct inflammation, simulating primary biliary cirrhosis, eczema, hemolytic anemia and hepatosplenomegaly (20, 
$25)$. In addition, deficiency of IL-10, a key $\operatorname{Tr} 1$ cytokine, results in uncontrolled inflammation at the mucosal surface (20).

Dysregulation in Treg cell frequency or functions may result in a plethora of autoimmune diseases, including multiple sclerosis, type 1 diabetes mellitus, myasthenia gravis, systemic lupus erythematodes, autoimmune lymphoproliferative syndrome, rheumatoid arthritis, and psoriasis, to name a few (37). Multiple sclerosis is an immune driven chronic demyelinating inflammatory disease. Its typical feature is lymphocyte infiltration and inflammation of the central nervous system. Impaired number and dysfunction in Treg cells may induce the overstimulation of CD4+ effector cells, resulting in the production of proinflammatory cytokines and neuronal damage (37). Type 1 diabetes mellitus is a chronic Th1 cell-mediated autoimmune disease resulting in the destruction of $\beta$ cells in the islets of Langerhans, that are producing insulin. Impaired suppression of the effector CD4+ and CD8+ T cells is involved in the pathogenesis of type 1 diabetes. This impaired suppression is caused by depression in several immunoregulatory subsets, including natural killer cells and Treg cells (37). Myasthenia gravis is an autoimmune disease affecting neuromuscular signal transmission. Patients with myasthenia gravis show a markedly diminished ability to suppress effector $\mathrm{T}$ cell proliferation. Therefore, the pathogenesis and progression of myasthenia gravis may be dependent on abnormal Treg cell functions (37). Systemic lupus erythematodes and autoimmune lymphoproliferative syndrome are chronic, systemic, autoimmune diseases. In their pathogenesis, decreased frequency of Treg cells is involved $(7,37)$. Rheumatoid arthritis is a chronic inflammatory disease accompanied by the destruction of joint architecture. The presence of proinflammatory cytokines plays a key role in the development and maintenance of rheumatoid arthritis. Treg cells in patients with rheumatoid arthritis are able to suppress effector $\mathrm{T}$ cell proliferation, but are incapable to suppress TNF- $\alpha$ and INF- $\gamma$ production. This suggests that dysfunction of Tregs' ability to suppress cytokine production contributes to etiology of rheumatoid arthritis (37). It is widely accepted that psoriasis is a systemic, predominantly $\mathrm{T}$ cell-mediated inflammatory disorder, with skin manifestation. Psoriasis is characterized by hyperproliferation and abnormal differentiation of keratinocytes with activated $\mathrm{T}$ cells and granulocytes accumulated in involved skin areas. Psoriatic Treg cells are functionally deficient in suppressing effector T cell responses. Although this deficiency is not absolute, higher numbers of psoriatic Treg cells are required to provide suppression similar to that of normal regulatory cells (30). These findings suggest that Treg cells are involved in the pathogenesis of psoriasis (21).

\section{Conclusion}

Self-tolerance is critical for the prevention of autoimmunity and maintenance of immune homeostasis. The abi- lity of the immune system to discriminate between self and nonself is controlled by mechanisms of central and peripheral tolerance.

Regulatory T cells (Tregs) are a specialized, phenotypically, and functionally distinct, subpopulation of $\mathrm{T}$ cells that modulate immune response, thereby maintaining homeostasis and self-tolerance. It has been shown that Tregs are able to inhibit $\mathrm{T}$ cell proliferation and cytokine production and play a critical role in preventing autoimmunity. Treg cells are accountable for hyporesponsiveness to tumor antigens and can be exploited to induce transplantation tolerance. $\mathrm{T}$ cells are considered to be of fundamental importance in a variety of immune disorders. Defect in a distinct Treg subset results in enhanced inflammatory reaction directed predominantly to the mucosal surfaces. Tregs are a good target for investigation of immunopathogenesis, diagnoses, treatment and/or prevention of immunological disorders.

\section{Acknowledgments}

This study was supported by Research project, Ministry of Health, Czech Republic, No. 00179906 and Ministry of Education, Czech Republic, project No. MSM0021620812. Supported in part by the Grant of Charles University in Prague, School of Medicine Hradec Kralove, sponsored by Roche company.

We thank Mrs. Hana Kotlandová for her graphic assistance.

\section{References}

1. Battaglia M, Gregori S, Bacchetta R, Roncarolo M-G. Tr1 cells: from discovery to their clinical application. Semin Immunol 2006;18(2):120-7.

2. Bettelli E, Carrier Y, Gao W et al. Reciprocal developmental pathways for the generation of pathogenic effector TH17 and regulatory T cells. Nature 2006; 441:235-8.

3. Bisikirska B, Colgan J, Luban J, Bluestone JA, Herold KC. TCR stimulation with modified anti-CD3 mAb expands CD8+ T cell population and induces CD8+CD25+ Tregs. J Clin Invest 2005;115:2904-13.

4. Dieckmann D, Plotter H, Berchtold S, Berger T, Schuler G. Ex vivo isolation and characterization of $\mathrm{Cd} 4+\mathrm{Cd} 25+\mathrm{T}$ cells with regulatory properties from human blood. J Exp Med 2001, 193(11):1303-10.

5. Fontenot JD, Rasmussen JP, Williams LM, Dooley JL, Farr AG, Rudensky AY. Regulatory $\mathrm{T}$ cell lineage specification by the forkhead transcription factor foxp3. Immunity 2005;22:329-41

6. Fontenot JD, Rudensky A. A well adapted regulatory contrivance: regulatory $\mathrm{T}$ cell development and the forkhead family transcription factor Foxp3. Nat Immunol 2005;6:331-7.

7. Franz B, Fritzsching B, Riehl A. Low number of regulatory T cells in skin lesions of patients with cutaneous lupus erythematosus. Arthritis Rheum 2007; 56(6): 1910-20

8. Furuzawa-Carballeda J, Vargas-Rojas MI, Cabral AR. Autoimmune inflammation from the Th17 perspective. Autoimmun Rev 2006;6:169-75.

9. Gondek DC, Lu LF, Quezada SA, Sakaguchi S, Noelle RJ. Cutting Edge: Contact-mediated suppression by $\mathrm{CD} 4^{+} \mathrm{CD} 25^{+}$regulatory cells involves a granzyme B-dependent, perforin-independent mechanism. J Immunol 2005; 174:1783-6.

10. Grant J, Bourcier K, Wallace S, et al. Validated protocol for FoxP3 reveals increased expression in type 1 diabetes patiens. Cytometry B Clin Cytom 2009;76B: 69-78.

11. Grossman WJ, Verbsky JW, Barchet W, Collona M, Atkinson JP, Ley TJ. Human $\mathrm{T}$ regulatory cells can use the perforin pathway to cause autologous target cell death. Immunity 2004;21:589-601.

12. Hirahara K, Liu L, Clark RA, Yamanaka K, Fuhlbrigge RC, Kupper TS. The Majority of Human Peripheral Blood CD4+CD25highFoxp3+ Regulatory T Cells Bear Functional Skin-Homing Receptors. J Imunol 2006;177:4488-94.

13. Hofmeister R, Khaled AR, Benbernou N, Rajnavolgyi E, Muegge K, Durum SK Interleukin-7: physiological roles and mechanisms of action. Cytokine Growth factor rev 1999;10:41-60. 
14. Hori S, Nomura T, Sakaguchi S. Control of regulatory T cell development by the transcription factor Foxp3. Science 2003, 299:1057-61.

15. Huber S, Schramm C, Lehr HA, et al. Cutting Edge: TGF- $\beta$ signaling si required for the in vivo expansion and immunosuppressive capacity of regulatory CD4 ${ }^{+} \mathrm{CD} 25^{+} \mathrm{T}$ cells. J Immunol 2004;173:6526-31.

16. Chen L, Shen Z, Wang G, Fan P, Liu Y. Dynamic frequency of CD4+CD25+ Foxp3+ Treg cells in Psoriasis vulgaris. J Dermatol Sci 2008 51(3):200-3.

17. Jonuleit H, Schmitt E, Stassen M, Tuettenberg A, Knop J, Enk AH. Identification and functional characterization of human $\mathrm{CD} 4^{+} \mathrm{CD} 25^{+} \mathrm{T}$ cells with regulatory properties isolated from peripheral blood. J Exp Med 2001;193:1285-94.

18. Kimball AB, Kupper TS. Future perspectives/quo vadis psoriasis treatment? Immunology, pharmacogenomics, and epidemiology. Clin Dermatol 2008;26:554-61.

19. Kursar M, Bonhagen K, Fensterle J, et al. Regulatory CD4+CD25+ T Cell Restrict Memory CD8+ T Cell Responses. J Exp Med 2002;196(12):1585-92.

20. Lan RY, Mackay JR, Gershwin ME. Regulatory T cells in the prevention of mucosal inflammatory diseases: Patrolling the bordur. J Autoimmun 2007;29:272-80.

21. Li Y-YY, Zollner TM, Schön MP. Targeting leukocyte recruitment in the treatment of psoriasis. Clin Dermatol 2008;26:527-38.

22. Liu W, Putnam AL, Xu-Yu Z, et al. CD127 expression inversely correlates with FoxP3 and suppressive function of human CD4+ T reg cells. J Exp Med 2006;203:1701-11.

23. Marie JC, Letterio JJ, Gavin M, Rudensky AY. TGF- $\beta 1$ maintains suppressor function and Foxp3 expression in CD4+CD25+ regulatory T cells. J Exp Med 2005, 201(7):1061-7.

24. Mosmann TR, Coffman RL. TH1 and TH2 cells: different patterns of lymphokine secretion lead to different functional properties. Annu Rev Immunol 1989;7:145-73.

25. Ochs HD, Oukka M, Torgerson TR. TH17 cells and regulatory T cells in primary immunodeficiency diseases. J Allergy Clin Immunol 2009;123(5):977-83.

26. Piccirillo CA, Shevach EM. Control of CD8+ T cell activation by CD4+CD25+ immunoregulatory cells. J Imunol 2001;167:1137-40.

27. Roncarolo MG, Bacchetta R, Bordignon C, Narula S, Levings MK. Type $1 \mathrm{~T}$ regulatory cells. Immunol Rev 2001;182:68-79.
28. Sakaguchi S, Sakaguchi N, Asano M, Itoh M, Toda M. Immunologic self-tolerance maintained by activated $\mathrm{T}$ cells expressing IL-2 receptor alpha-chains (CD25). Breakdown of a single mechanism of self-tolerance causes various autoimmune diseases. J Immunol 1995; 155:1151-64.

29. Sakaguchi S. Naturally arising Foxp3-expressing CD25+CD4+ regulatory T cells in immunological tolerance to self and non-self. Nat Immunol 2005:6:345-52.

30. Sugiyama H, Gyulai R, Toichi E, et al. Dysfunctional blood and target tissue $\mathrm{CD} 4+\mathrm{CD} 25$ high regulatory $\mathrm{T}$ cells in psoriasis: mechanism underlying unrestrained pathogenic effector $\mathrm{T}$ cell proliferation. J Immunol 2005;174: 164-73

31. Taams LS, Van Amelsfort JM, Tiemessen MM, et al. Modulation of monocyte/macrophage function by human $\mathrm{CD} 4+\mathrm{CD} 25+$ regulatory T cells. Hum Imunol 2005;66:222-30

32. Thornton AM, Shevach EM. CD4+CD25+ immunoregulatory T cells supress polyclonal $\mathrm{T}$ cell activation in vitro by inhibiting interleukin 2 production. $\mathrm{J}$ Exp Med 1998;188:287-96.

33. Trzonkowski P, Szmit E, Mysliwska J, Dobyszuk A, Myśliwski A. CD $4^{+} \mathrm{CD} 25^{+}$ $\mathrm{T}$ regulatory cells inhibit cytotoxic activity of $\mathrm{T} \mathrm{CD} 8^{+}$and NK lymphocytes in the direct cell-to-cell interaction. Clin Immunol 2004;112:258-67.

34. Veldhoen M, Hocking RJ, Atkins CJ, Locksley RM, Stockinger B. TGF beta in the context of an inflammatory cytokine milieu supports de novo differentiation of IL-17-producing T cells. Immunity 2006;24:179-89.

35. Verhagen J, Akdis M, Traidl-Hoffmann C, et al. Absence of T-regulatory cell expression and function in atopic dermatitis skin. J Allergy Clin Immunol 2006;117(1):176-83

36. Veselá I, Stř́iž I. T regulační buňky a jejich úloha v imunitních reakcích. Alergie 2004;1:43-52.

37. Vojdani A, Erde J. Regulatory T cells, a potent immunoregulatory target for CAM researchers: modulating tumor immunity, autoimmunity and alloreactive immunity (III). eCAM 2006;3(3):309-16.

38. Zheng SG, Wang J, Wang P, Gray JD, Horwitz DA. IL-2 Is Essential for TGF- $\beta$ to Convert Naive CD4+CD25+ Cells to CD25+Foxp3+ Regulatory T Cells and for Expansion of These Cells. J Immunol 2007, 178(4):2018-27.

Received: $21 / 01 / 2010$.

Accepted in revised form: 18/03/2010.

\section{Corresponding author:}

Kateřina Kondělková, MSc., Charles University in Prague, University Hospital Hradec Králové, Department of Clinical Immunology and Allergology, Sokolská 581, 50005 Hradec Králové, Czech Republic; e-mail: katerina.kondelkova@seznam.cz 